\title{
Poder tributario local y reserva de ley ante la próxima reforma del Gobierno local
}

\author{
María José Fernández Pavés \\ Profesora Titular de Derecho Financiero y Tributario \\ Antonia Jabalera Rodríguez \\ Doctora con mención europea \\ Universidad de Granada
}

\begin{abstract}
Sumario: I. INTRODUCCIÓN. II. RECONOCIMIENTO CONSTITUCIONAL E IMPLICACIONES DEL PODER NORMATIVO DE LOS ENTES LOCALES EN MATERIA TRIBUTARIA. III. PRINCIPIOS DE RESERVA DE LEY Y DE AUTONOMÍA LOCAL: A) Consideraciones generales sobre el principio de reserva de ley en materia tributaria. B) La reserva de legalidad en los tributos propios locales y su interrelación con la autonomía local. C) Las ordenanzas fiscales como manifestación del poder tributario local. IV. CONFIGURACIÓN DEL PODER TRIBUTARIO LOCAL EN LAS LEYES ORDINARIAS. V. DESARROLLO DE LA LGT POR LOS REGLAMENTOS LOCALES. VI. CONCLUSIÓN.
\end{abstract}

\section{INTRODUCCIÓN}

En un momento en el que se debate política y socialmente sobre el modelo de organización territorial del Estado, aunque bien es cierto que dicho debate lamentablemente sólo se encuentra centralizado entre el Estado y las Comunidades Autónomas, con la tramitación y aprobación de los diversos Estatutos de Autonomía, se ha iniciado paralelamente un proceso de reforma del sistema de organización y funcionamiento de las Entidades locales, y del que se prevé derive la aprobación de una nueva Ley de Bases que las regule. Como ya sucediera en los primeros años de andadura democrática, este debate local se ha visto eclipsado por el autonómico; cuando quizá, para evitar reincidir en errores del pasado, debiera aprovecharse el momento para afrontar un verdadero diálogo sobre la distribución de competencias y de recursos financieros entre los tres niveles territoriales. No estaría de más que se otorgase, de una vez por todas, el reconocimiento y protagonismo que se merece, al que puede llamarse Estatuto de Autonomía Local.

De otro lado, centrando nuestra atención en esta nueva reforma de la Administración Local, que constituye un eslabón más en el arduo proceso de modernización y racionalización de los Gobiernos locales, reforzando su autonomía y autosuficiencia; no podemos dejar de mencionar lo llamativo que resulta que se esté perfilando un nuevo texto básico sobre el Gobierno y la Administración Local, con una novedosa distribución de competencias, sin que se acompañe de un debate simultáneo sobre su financiación.

Una de las pretensiones de este nuevo modelo de organización y funcionamiento de la Entidad local es precisamente dotar a ésta de mayores com- 
petencias, y sobre todo, otorgar un reconocimiento normativo a aquéllas que de hecho vienen ejerciendo, pese a estar atribuidas a otros niveles de gobierno que cuentan con más recursos financieros y resultan menos próximos o cercanos a los ciudadanos, respondiendo así a la reivindicación realizada por los propios Municipios ${ }^{1}$. En este sentido, se pretende incorporar una cláusula general de competencia a favor de los municipios en línea con lo que viene establecido en el art. 4.2 de la Carta Europea de Autonomía Local ${ }^{2}$, reconociéndoles la capacidad de actuar sobre todas aquellas materias que sean de interés local y no se encuentren atribuidas al Estado o a las Comunidades Autónomas; disponiendo a tal efecto de las potestades de planificación, normativa y de gestión (art. 17 del Borrador de Anteproyecto de Ley Básica del Gobierno y la Administración local presentado el pasado 22 de noviembre de 2005) ${ }^{3}$. Se consigue de este modo, o al menos así se pretende, reconocer al municipio la capacidad de detectar las necesidades de sus ciudadanos y de convertir las soluciones en competencias ${ }^{4}$.

Más competencias significan irremediablemente mayores costes para los Entes que las asumen y, en consecuencia, la necesidad de contar con una financiación que permita ejercerlas con eficacia y eficiencia, respondiendo así a las necesidades y demandas ciudadanas. No cabe duda de que, para ello, se habrá de incrementar, como ya sucediera con la Ley 51/2002, de 27 de diciembre, de reforma de la Ley 39/1988, de 28 de diciembre, reguladora de las Haciendas Locales, la participación de los Entes locales en los tributos estatales y autonómicos ${ }^{5}$; aunque en este último caso, más que de incrementar,

\footnotetext{
${ }^{1}$ Tal y como se reconoce en el Libro Blanco para la Reforma del Gobierno Local en España, presentado el pasado 10 de enero de 2005 «ésta es una realidad que comienza a ser habitual en muchos mиnicipios españoles que han desarrollado experiencias de planificación estratégica, constando que muchas de las competencias que necesitaban activar se hallaban en otros niveles de gobierno con menor información y más recursos económicos. Esta frustración les ha llevado a reivindicar mas competencias y más financiación. Es esta situación insatisfactoria la que motiva la redacción de este Libro».

${ }^{2}$ Dispone este art. 4.2 CEAL que «las Entidades locales tienen, dentro del ámbito de la Ley, libertad plena par ejercer su iniciativa en toda materia que no esté excluida de su competencia o atribuida a otra autoridad».

3 Junto a esta cláusula general de competencia, existen otros dos mecanismos a través de los cuales se pretenden atribuir competencias a las Entidades locales: de un lado, se recoge un listado de materias, que constituye una refundición de los vigentes arts. 25.2 y 26 de la Ley 7/1985, de 2 de abril, reguladora de las Bases de Régimen Local sobre las que los Municipios tiene competencia (art. 18 Anteproyecto), y entre los que se encuentran los servicios obligatorios locales (art. 19 Anteproyecto). De otro lado, se sitúan un elenco de materias respecto de las que la legislación estatal y autonómica ha de garantizar la intervención municipal, mediante la atribución de potestades de planificación, normativa y de gestión. Entre éstas últimas se sitúan: consumo, cultura, deportes, educación, empleo, inmigración, juventud, medio ambiente, ordenación del territorio, etc., y en definitiva, «cualquier otra materia de competencia del Estado o de la Comunidad Autónoma, cuya gestión, total o parcial, se considere que deba ser realizada por las entidades locales, en virtud de los principios de subsidiariedad, descentralización y cercanía o proximidad al ciudadano» (art. 20 Anteproyecto).
}

${ }^{4}$ Así se señala en el Libro Blanco para la Reforma del Gobierno Local en España presentado el 10 de enero de 2005.

${ }^{5}$ En este sentido puede consultarse FERnÁNDEZ PAVÉs, M.J.: «La suficiencia financiera local: algunas reflexiones de cara a la reforma», Revista de Estudios Locales, CUNAL, n. ${ }^{\circ} 63,2003$, ps. 37 y ss. 
PODER TRIBUTARIO LOCAL Y RESERVA DE LEY ANTE LA PRÓXIMA REFORMA...

debe hablarse de poner efectivamente en práctica dicha participación que goza de reconocimiento constitucional (art. $142 \mathrm{CE}$ ). Pero, también esas necesidades financieras deberán en parte satisfacerse con los ingresos derivados de sus tributos propios; y para ello, resultará esencial, como se ha demostrado en estos últimos años, que estos Entes cuenten con facultades normativas reales y efectivas que les permitan programar, diseñar y modular su política global de ingresos públicos municipales.

Precisamente, el objetivo de este trabajo es analizar el alcance de las facultades normativas de que disponen, hoy en día, los Municipios en el ámbito tributario, partiendo de su encuadre constitucional y de su plasmación normativa, que se ha visto decisivamente impregnada por la necesaria conciliación de dos principios esenciales, como son el de autonomía local y el de reserva de ley tributaria; para, a partir del balance actual de la capacidad normativa de estos Entes, concluir acerca de una conveniente modificación en la próxima reordenación del Gobierno local.

\section{RECONOCIMIENTO CONSTITUCIONAL E IMPLICACIONES DEL PODER NORMATIVO DE LOS ENTES LOCALES EN MATERIA TRIBUTARIA}

El reconocimiento del poder normativo local se encuentra implícito en la propia declaración constitucional de autonomía de las Corporaciones locales «para la gestión de sus respectivos intereses» (art. 137 y $140 \mathrm{CE}$ ), dado que, si dicha autonomía comporta, entre otras consecuencias, «la adopción, dentro de su ámbito competencial, de decisiones políticas entre varias alternativas posibles, lógicamente dichas decisiones se materializan o plasman en normas dictadas por el ente que goza» de ella ${ }^{6}$. Así se infiere de la propia definición que se contiene en la Carta Europea de Autonomía Local, identificando autonomía local con «el derecho y la capacidad efectiva de las Entidades locales de ordenar y gestionar una parte importante de sus asuntos públicos, en el marco de la Ley, bajo su propia responsabilidad y en beneficio de sus habitantes»; y cuyo tenor literal precisamente se proyecta incorporar en la futura Ley Básica de Gobierno y la Administración Local ${ }^{7}$. Vemos, por tanto, cómo este principio constitucional de autonomía municipal, es de por sí suficiente para sustentar y declarar la existencia a favor del Ente local de un poder normativo propio, y por cuanto nos interesa, de un poder para establecer y exigir tributos; así como, al mismo tiempo, se erige en garante del mismo, como veremos ${ }^{8}$.

\footnotetext{
${ }^{6}$ Aníbarro Pérez, S.: «Las competencias normativas de las Corporaciones locales sobre sus tributos locales», Revista de Estudios Locales, CUNAL, n. ${ }^{\circ}$ 42, 2000, p. 53.

7 Se insiste en el Libro Blanco que la autonomía local es una autonomía política en el marco de la Constitución, y no una autonomía administrativa en el marco de la ley.

${ }^{8}$ FERnÁndeZ PAvés, M.J.: «La suficiencia financiera local...», cit.
} 
Pero nuestro texto constitucional no se limita a hacer un reconocimiento implícito de dicho poder normativo, sino que expresamente lo proclama en el art. 133.2 del mismo al señalar que «las Comunidades Autónomas y las Corporaciones locales podrán establecer y exigir tributos, de acuerdo con la Constitución y las leyes» ${ }^{9}$; de manera que se le dota de un rango constitucional, que obviamente vincula a toda la legislación posterior, o dicho en otros términos, se consigue de esta manera impedir que dicho poder quede al arbitrio del legislador, cuyas previsiones no podrán en ningún caso vaciar de contenido o reducir hasta niveles insignificantes el mandato constitucional ${ }^{10}$.

Ahora bien, este poder tributario está igualmente condicionado en su ejercicio, no se configura con un carácter absoluto, sino que se encuentra sometido a determinados límites derivados de la Constitución y las Leyes; nos encontramos, en definitiva, ante un poder limitado (o si se prefiere, derivado) ${ }^{11}$, cuya definición, contenido y alcance será precisado por la legislación de desarrollo de la Constitución (el llamado bloque de constitucionalidad). Al hacerlo, habrán de salvaguardarse o respetarse varios principios constitucionales, entre los que juegan un papel básico y esencial para el tema que nos ocupa, el necesario respeto a la autonomía y suficiencia financiera local (arts. 137 y $142 \mathrm{CE}$ ), que actuarán a su vez como límites a tales disposiciones legales, así como un principio básico en el ámbito tributario, como es el de reserva de ley (art. 31.3 CE).

\section{PRINCIPIOS DE RESERVA DE LEY Y DE AUTONOMÍA LOCAL}

De la conjunción y ponderación de estos últimos principios, autonomía, suficiencia y reserva de ley, básicamente, y del mayor o menor protagonismo que se quiera otorgar a cada uno de ellos por parte del legislador, siempre, claro está, dentro del marco constitucional; se derivará el alcance concreto de las facultades normativas que se reconocen a las Corporaciones locales

\footnotetext{
${ }_{9}^{9}$ Evidentemente, pese a que el texto constitucional parezca equipararlos, el poder tributario que se confía a los Entes locales es sustancialmente más limitado que el atribuido a las Comunidades Autónomas. De ahí que la referencia al establecimiento de tributos sea distinta en significado, contenido y alcance, según aluda a las Comunidades Autónomas o a las Entidades locales. Tal y como se ha reconocido, las Comunidades Autónomas pueden establecer tributos en su sentido pleno, de crear tributos ex novo mediante una ley que los fije, lo cual, por razones obvias, no pueden hacer las Entidades locales.

${ }^{10}$ Vid. Lozano SerRano, C.: «Potestades tributarias de las Entidades locales», Palau 14, RVHL, n. ${ }^{\circ} 18$, 1992, p. 9; y Ramallo Massanet, J., y Zornoza Pérez, J.: «Autonomía y suficiencia financiera en la financiación de las Haciendas Locales», Revista de Estudios de la Administración Local y Autonómi$c a$, n. ${ }^{\circ} 259,1993$, p. 507.

${ }^{11}$ Que se trate de un poder limitado, y sustancialmente más limitado que el reconocido a las Comunidades Autónomas, no puede llevarnos a calificarlo, como sí han hecho algunos autores, entre los que se encuentran AlbiÑana CilvetTi, como un poder «meramente nominal» («Las ordenanzas fiscales como fuente del derecho», en Organización territorial del Estado (Administración local), Volumen I, IEF, Madrid, 1985, p. 414).
} 
PODER TRIBUTARIO LOCAL Y RESERVA DE LEY ANTE LA PRÓXIMA REFORMA...

sobre sus tributos propios. Como indicamos, juega un papel esencial en la definición y delimitación del poder normativo local en materia tributaria, el principio de reserva de ley; pues, en principio, este ámbito de decisión normativa, vendrá determinado en sentido negativo, por la facultad de dictar normas respecto de todos aquellos elementos y aspectos del tributo, no cubiertos específicamente por la reserva de ley estatal ${ }^{12}$.

\section{A) Consideraciones generales sobre el principio de reserva de ley en materia tributaria}

Muy brevemente vamos a tratar de perfilar los elementos básicos del principio de reserva de ley en materia tributaria; que el art. 31.3 CE proclama genéricamente con respecto a cualquier prestación personal o patrimonial de carácter público, categoría genérica en cuyo seno se integran las prestaciones tributarias, junto a aquéllas otras también caracterizadas por su coactividad.

Según la teoría general de las fuentes, este principio incide sobre las relaciones entre diversos poderes de un mismo ordenamiento, actuando ad intra de él y no como regla delimitadora de competencias entre entes pertenecientes a ordenamientos diversos. Preside fundamentalmente las relaciones entre Constitución y Ley; es una norma sobre la producción normativa — «norma sulla normazione» según Giannini- que determina qué materias necesaria e inexcusablemente habrán de ser reguladas por Ley, sin que pueda el legislador ordinario, en consecuencia, disponer de ellas procediendo a su deslegalización; no obstante, ello no significa que el Reglamento no pueda entrar a desarrollar aspectos no esenciales de dichas materias, si bien, en tal caso, deberá hacerlo teniendo en cuenta lo dispuesto previamente en una norma de rango legal; no puede olvidarse que una norma reglamentaria es una norma complementaria de la Ley, subordinada en consecuencia a la misma.

Este principio, cuyo fundamento se ha ubicado principalmente en el necesario respeto al principio de autoimposición e igualdad ${ }^{13}$, y al que se ha

\footnotetext{
12 MenÉndez Moreno, A.: «El poder tributario de las Corporaciones locales», en Organización territorial del Estado (Administración local), Volumen III, IEF, Madrid, 1985, ps. 2109 y 2112.

13 Tradicionalmente se ha sostenido, y aún hoy puede seguir sosteniéndose, que el fundamento de este principio se encuentra en la necesaria salvaguarda de la primacía de la voluntad general, o si se prefiere, de la autoimposición por los ciudadanos de sus prestaciones tributarias; en palabras del Tribunal Constitucional se trata de «asegurar que la regulación de un determinado ámbito vital de las personas dependa exclusivamente de la voluntad de sus representantes» (STC 19/1987, de 17 de febrero, F.J. 4). Asimismo, «es también, en nuestro Estado constitucional democrático, una consecuencia de la igualdad y por ello preservación de la paridad básica de posición de todos los ciudadanos, con relevancia, no menor, de la unidad misma del ordenamiento» (STC 19/1987, F.J. 4); sin olvidar, que favorece la consecución de la seguridad jurídica, entendida como certeza en el derecho. Finalmente, se considera que se encuentra al servicio del logro del sistema tributario justo al que se refiere el art. $31.3 \mathrm{CE}$, pues «la ley resulta ser el vehículo idóneo para desplegar de modo ajustado las expectativas de justicia material» (Cubero Truyo, A.M.: «La doble relatividad de la reserva de ley en materia tributaria. Doctrina constitucional», Civitas, REDF, n. ${ }^{\circ} 109-110,2001$, pp. 218 y 219).
} 
atribuido una finalidad garantista del derecho a la propiedad (STC 19/1987, de 17 de febrero), preside las relaciones entre el Legislativo y el Ejecutivo en cuanto a la producción de normas, así como constituye un límite para ambos poderes, en cuanto impone al primero la obligación de regular una determinada materia, y al segundo la de abstenerse de intervenir, salvo en aquellos supuestos en los que, dentro del marco constitucional, sea adecuadamente habilitado ${ }^{14}$.

Distinto de este principio de reserva de ley, es el de preferencia de ley, que igualmente actuará como límite al ejercicio de sus facultades normativas por los Entes locales. Este principio, en términos generales, preside las relaciones entre Ley y Reglamento, de forma que un Reglamento no puede contradecir lo dispuesto en una Ley, y una materia regulada por Ley no puede ser regulada por un Reglamento; la articulación de las relaciones entre ambos, se produce bajo el principio de jerarquía normativa, que supone la subordinación del Reglamento a la Ley; de lo que se deduce que «el Reglamento complementa la Ley, pero no puede ni derogarla ni suplirla, ni menos aún limitarla o excluirla. La Ley frente al Reglamento, a su vez, no tiene límites de actuación funcionalizables» ${ }^{15}$.

En materia tributaria, esta reserva de ley no tiene un carácter absoluto, sino relativo ${ }^{16}$; debe abarcar, en palabras del Tribunal Constitucional, «los criterios o principios con arreglo a los cuales se ha de regir la materia tributaria: la creación ex novo de un tributo y la determinación de los elementos esenciales o configuradores del mismo» ${ }^{17}$. La pregunta inmediata que surge es, evidentemente, cuáles son dichos elementos esenciales; habiendo sido el Tribunal Constitucional el encargado de concretar, qué aspectos materiales del tributo se encuentran necesariamente cubiertos por la reserva de ley; aunque, cierto es que, en ocasiones, no lo ha hecho con la claridad y precisión que cabría esperar del máximo intérprete de la Constitución.

Partiendo de la premisa de que la reserva de ley en materia tributaria no afecta por igual a todos los elementos integrantes del tributo, ha señalado que el grado de concreción exigible a la ley es máximo cuando regula el hecho imponible y/o el establecimiento de beneficios fiscales ${ }^{18}$, y menor en rela-

\footnotetext{
${ }^{14}$ Interesantes son las consideraciones que sobre el principio de reserva de ley realizan GARCÍA DE Enterría, E., y Fernández, T.R.: Curso de Derecho Administrativo I, Civitas, Madrid, 1999, p. 230.

15 Ibid., p. 230.

${ }^{16}$ Como ratifica la expresión «... con arreglo a la ley» empleada en el art. $31.3 \mathrm{CE}$, y «... mediante ley» del art. 133.1 CE, y ha confirmado el Tribunal Constitucional en sus Sentencias 37/1981, 6/1983, de 4 de febrero (F.J. $4^{\circ}$ y $6^{\circ}$ ), 179/1985 y 19/1987, entre otras.

${ }_{17}$ SSTC 37/1981, F.J. 4. ${ }^{\circ}$, 6/1983, F.J. 4. ${ }^{\circ}$, 179/1985, F.J. 3. ${ }^{\circ}$, 19/1987, F.J. 4. ${ }^{\circ}$, y 185/1995, F.J. 5. ${ }^{\circ}$

${ }_{18}$ Curiosamente, en su Sentencia 6/1983, de 4 de febrero, aclaró el TC que la reserva de ley afecta al establecimiento de exenciones y bonificaciones tributarias, «pero no cualquiera otra regulación de ellas, ni la supresión de las exenciones o su reducción o la de las bonificaciones, porque esto último no constituye alteración de elementos esenciales del tributo» (F.J.6), lo cual ha suscitado importantes críticas doctrinales.
} 
PODER TRIBUTARIO LOCAL Y RESERVA DE LEY ANTE LA PRÓXIMA REFORMA...

ción a otros elementos, como el tipo de gravamen y la base imponible (STC 221/1992 F.J. 7. $\left.{ }^{\circ}\right)^{19}$.

Al tratarse de una reserva relativa, resulta admisible la intervención y colaboración del reglamento, siempre que «sea indispensable por motivos técnicos o para optimizar el cumplimiento de las finalidades propuestas por la Constitución o por la propia Ley» ${ }^{20}$, y además, siempre que la colaboración se produzca «en términos de subordinación, desarrollo y complementariedad» ${ }^{21}$. El alcance de esta colaboración «estará en función de la diversa naturaleza de las figuras jurídico-tributarias y de los distintos elementos de las mismas» (STC 185/1995), ya que esta reserva de ley no alcanza por igual a todas las categorías tributarias; sus exigencias se mitigan cuando se trata de tasas y contribuciones especiales, mientras que se muestran con mayor rigurosidad en el ámbito de los impuestos ${ }^{22}$. De lo anterior, se colige la práctica imposibilidad de determinar a priori el ámbito admisible de intervención del Reglamento, en la regulación de los elementos del tributo reservados a la ley; pues dado que ésta admite diversos grados de flexibilidad en función

\begin{abstract}
${ }^{19}$ Sobre el alcance del principio de reserva de ley en materia tributaria, la concreción de los elementos amparados por dicha reserva y el grado de cobertura exigible a la norma legal puede consultarse, entre otros, los siguientes trabajos doctrinales: CALVo ORTEGA, R.: «Constitución y Haciendas Locales», Civitas, REDF, n. ${ }^{\circ}$ 100, 1998; CheCa GonZÁlez, C.: «El Principio de reserva de ley en materia tributaria», Estudios de Derecho y Hacienda, Ministerio de Hacienda, Madrid, 1987; Falcón Y Tella, R.: «Un principio fundamental del Derecho tributario: la reserva de ley», Civitas, $R E D F$, n. ${ }^{\circ}$ 104, 1999; FERREIRo LAPATZA, J.J.: «Principio de legalidad y las relaciones entre Ley-Reglamento en el ordenamiento tributario español», en Estudios de Derecho y Hacienda, Volumen II, IEF, Madrid, 1987; GARCÍA AÑoveros, J.: «Las fuentes del Derecho en la Ley General Tributaria», RDFHP, n. ${ }^{\circ} 54,1964$; GoNZÁLEZ GARCíA, E.: «El principio de legalidad tributaria en la Constitución Española de 1978», en La Constitución Española y las fuentes del Derecho, Volumen II, IEF, Madrid, 1991; MenÉndez MoreNo, A.: «El poder tributario de las Corporaciones locales», en Organización territorial del Estado (Administración local), Volumen III, IEF, Madrid, 1985, y de este mismo autor, «Algunas reflexiones sobre los principios de capacidad y legalidad como inspiradores de los tributos y de los precios públicos», en Estudios de Derecho Tributario. En memoria de María del Carmen Bollo Arocena, Servicio editorial de la Universidad del País Vasco, Bilbao, 1993; Palao TABoada, C.: «Reserva de ley y reglamentos en materia tributaria», en Funciones financieras de las Cortes Generales, Madrid, 1985; PÉREZ Royo, F.: «Fundamento y ámbito de la reserva de ley en materia tributaria», Hacienda Pública Española, n. ${ }^{\circ} 14,1972$, y del mismo autor, «Principio de legalidad, deber de contribuir y Decretos-leyes en materia tributaria»; REDC, n. ${ }^{\circ}$ 13, 1985; TeJERIZo LÓPEZ, J.M.: «Las fuentes del derecho financiero a la luz de la Constitución», en La Constitución Española y las fuentes del Derecho, Volumen III, Instituto de Estudios Fiscales, Madrid, 1979; Vega Herrero, M.: «Inconstitucionalidad del recargo municipal sobre el IRPF (Comentario a la STC de 19 de diciembre de 1985)», La Ley, n. ${ }^{\circ}$ 3, 1986.
\end{abstract}

${ }^{20}$ Acoge, por tanto, el Tribunal Constitucional al determinar la extensión admisible de la intervención
del reglamento en el campo reservado a la ley, el llamado criterio del «complemento indispensable»,
conforme al cual «el Reglamento, que habrá de ser forzosamente un Reglamento ejecutivo, ha de limi-
tarse a adoptar las medidas estrictamente necesarias para la aplicación de la ley, sin que pueda agravar
las cargas y obligaciones contenidas en la ley ni añadir a los preceptos de ésta otros nuevos no justifi-
cados por dicha necesidad. Ello supone un cierto margen de apreciación administrativa, como es obvio,
pero plenamente accesible al control jurisdiccional». Ahora bien, este criterio, como reconoce FALCóN
Y TeLLA, «no resuelve enteramente el problema de la intensidad de la reserva de ley tributaria» («La
reserva de Ley en el art. 8 de la nueva LGT (y III): límites a la intervención del reglamento y de las
órdenes ministeriales»; Quincena Fiscal, n. ${ }^{\circ}$ 10, 2004.)

${ }^{21}$ Entre otras, SSTC 37/1981, 6/1983, 60/1986, 79/1986, 19/1987 y 99/1987.

${ }^{22}$ SSTC 37/1981, FJ $4^{\circ}$, y 19/1987, FJ. $4^{\circ}$. 
del supuesto de que se trate, sólo a través de un análisis individualizado caso por caso, podrá determinarse un posible exceso reglamentario en el desarrollo o ejecución de la ley, o una excesiva deslegalización de la norma legal ${ }^{23}$.

Pero la reserva de ley no sólo incide en el ámbito material del tributo, sino que también despliega su operatividad en la esfera procedimental de la prestación tributaria; tal y como se infiere de la exigencia del art. 31.3 de la CE de una norma de rango legal para el establecimiento de prestaciones patrimoniales y personales de carácter público, así como, del art. 105 de la Constitución, que determina que la Ley regulará «el procedimiento a través del cual deben producirse los actos administrativos, garantizando, cuando proceda, la audiencia del interesado» ${ }^{24}$. Sobre el alcance de la reserva en este ámbito, se ha propuesto para su determinación un criterio similar al sostenido por el Tribunal Constitucional, entre otras, en su Sentencia 221/1992, de 14 de diciembre, anteriormente mencionada, al referirse a los elementos materiales del tributo cubiertos por este principio; de modo que, si se generaliza la afirmación contenida en dicho pronunciamiento a todos los supuestos contenidos en el art. 31.3 de la CE, puede afirmarse que, tanto la creación de cualquier prestación personal pública obligatoria para los ciudadanos, así como la regulación de sus principales aspectos o elementos sustanciales, junto con la delimitación de las líneas directrices o básicas y más relevantes de los procedimientos de aplicación de los tributos, habrá de determinarse en una norma legal ${ }^{25}$.

\section{B) La reserva de legalidad en los tributos propios locales y su interrelación con la autonomía local}

Las anteriores consideraciones, bastante breves y generales, sobre el principio de reserva de ley tributaria, no pueden trasladarse sin introducir cier-

\footnotetext{
${ }^{23}$ Véase las consideraciones realizadas al respecto por FALCón y TelLA, R: «La reserva de ley en el art. 8 de la nueva LGT (y III): límites a la intervención del reglamento y de las Órdenes ministeriales», Quincena fiscal, n. ${ }^{\circ} 10,2004$.

${ }^{24}$ El Tribunal Constitucional en su Sentencia 110/1984, de 26 de noviembre, considera los deberes y obligaciones formales como una manifestación del deber de contribuir, y en su Sentencia 76/1990, de 26 de abril, subraya la necesaria intervención del legislador para establecer potestades administrativas (como las de inspección y obtención de información) y los correlativos deberes de los ciudadanos (F.J. 3). Al respecto, véase el comentario que sobre la existencia y alcance de la reserva de ley en el ámbito de los deberes formales realiza FALCón Y Tella, R.: «La reserva de Ley en el art. 8 de la nueva LGT (II): obligaciones tributarias a cuenta, accesorias entre particulares y de hacer o formales», Quincena Fiscal, n. ${ }^{\circ}$ 9, 2004.
}

Por su parte, en la Sentencia de la Audiencia Nacional de 28 de febrero de 1995 se reconoce que «la obligación de proporcionar a la Administración Tributaria, datos, informes o antecedentes con transcendencia tributaria, constituye una manifestación de los llamados doctrinalmente «deberes de colaboración»..., encuadrables en la categoría más amplia de los deberes de prestación a que implícitamente se refiere el artículo $31.3 \mathrm{CE}$.

${ }^{25}$ Véase al respecto nuestro trabajo, Fernández PAVÉs, M.J.: «Implicaciones del Principio constitucional de legalidad tributaria en el ámbito procedimental del tributo», en Estudios de Derecho Público. Homenaje a Juan José Ruiz Rico, Tecnos, Madrid, 1997, pp. 272 y 273. 
PODER TRIBUTARIO LOCAL Y RESERVA DE LEY ANTE LA PRÓXIMA REFORMA...

tas e importantes matizaciones, al concreto y específico ámbito local. De realizar dichas matizaciones se ha encargado, como no podía ser de otro modo, el Tribunal Constitucional; el cual a través de sus diversos pronunciamientos, ha ido concretando el alcance de este principio cuando se proyecta sobre los tributos locales, buscando un equilibrio con el de autonomía financiera de las Corporaciones locales, del que constituye su principal límite ${ }^{26}$.

En un principio, no había lugar a dudas: la especificidad de la reserva de ley le otorgaba a ésta un carácter prevalente o prioritario sobre la autonomía local, y en consecuencia, un cierto carácter residual a la autonomía ${ }^{27}$. Paulatinamente, a través de los distintos pronunciamientos del Tribunal Constitucional sobre los tributos propios locales, este planteamiento, sin desaparecer, ha ido virando hacia posiciones más flexibles; ampliándose el ámbito de decisión normativa de las Corporaciones locales y suavizándose, en consecuencia, el rigor en la interpretación de la reserva de ley cuando se proyecta sobre la esfera local.

Ya en sus primeras Sentencias expresamente referidas al sistema tributario local, como son la 179/1985, de 19 de diciembre, y 19/1987, de 17 de febrero, que declararon respectivamente la inconstitucionalidad de la facultad otorgada a los Ayuntamientos por la Ley 24/1983, de 21 de diciembre, de Saneamiento y Regulación de las Haciendas Locales para fijar libremente el tipo de gravamen del Recargo Municipal sobre el IRPF y los tipos de gravamen de las Contribuciones Territoriales; reconoció el Tribunal Constitucional que no se puede ignorar, cuando se trata de ordenar por Ley los tributos locales, que la reserva de Ley «ve confirmada su parcialidad, esto es, la restricción de $s u$ ámbito» ${ }^{28}$, pues el sentido que hay que reconocer a este principio constitucional introducido por el art. 31.3 CE, no puede entenderse desligado de las condiciones propias del sistema de autonomías territoriales

\footnotetext{
${ }^{26}$ Una de las consideraciones que se deducen de los pronunciamientos del Tribunal Constitucional es que en materia tributaria local nos encontramos ante una reserva estatal de Ley. Así se repite en diversas ocasiones en la STC 233/1999, de 16 de diciembre, en cuyo Fundamento Jurídico $10^{\circ}$ se indica que «...procura la Constitución en el artículo 133 integrar las diversas exigencias derivadas de la reserva de ley estatal, y de la autonomía territorial...»; y más adelante que «en virtud de la autonomía de los Entes locales... es preciso que la Ley estatal atribuya a los Acuerdos dictados por éste...»; y en el fundamento 22 que «aquella reserva habrá de operar necesariamente a través del legislador estatal, cuya intervención reclaman los apartados 1 y 2 del artículo 133 de la Constitución, en tanto en cuanto existe también al servicio de otros principios _la preservación de la unidad del ordenamiento y de una básica igualdad de posición de los contribuyentes-, principios que sólo puede satisfacer la ley del Estado».

27 En este sentido, CAlvo Ortega considera que «la reserva de ley es... de consideración jurídica preferente», y por tanto, «en una secuencia lógica primero será el establecimiento por Ley (contenido mínimo) y después el respeto a la autonomía municipal» («Principios tributarios y Reforma de la Hacienda Pública», en La Reforma de las Haciendas Locales, Tomo I, Lex Nova, Valladolid, 1991, p. 50).

${ }^{28}$ STC 19/1987, F.J.4 ${ }^{\circ}$, posteriormente reiterado, entre otras, en su Sentencia 233/1999, F.J. $10^{\circ}$, que compendia toda su doctrina constitucional sobre esta materia.
} 
que la Constitución consagra (art. 137) y específicamente de la garantía constitucional de la autonomía de los municipios (art. 140) ${ }^{29}$.

En efecto, la proclamación constitucional de la autonomía de las Corporaciones locales «posee también una proyección en el terreno tributario», y en consecuencia, «éstas habrán de contar con tributos propios y sobre los mismos deberá la Ley reconocerles una intervención en su establecimiento o en su exigencia (art. 140 y 133.2)...; ello sin perjuicio de que esta autonomía tributaria no sea plena y de que no aparezca la misma carente de límites» ${ }^{30}$.

De otro lado, la reserva de ley en el ámbito local ha de actuar con una mayor «parcialidad» o «restricción» si se tiene en cuenta, además, que la imposición y ordenación de los tributos locales corresponde al Pleno de la Corporación, «órgano que, en tanto que integrado por todos los Concejales (art. 22.1 LBRL) elegidos, en los términos que establece la legislación electoral general «mediante sufragio universal, igual, libre, directo y secreto» (art. 19.2 LBRL), respeta escrupulosamente las exigencias de autoimposición o autodisposición de la comunidad sobre sí misma que... se adivinan en el sustrato último de la reserva de ley» (STC 233/1999, F.J. 10) ${ }^{31}$. «Los Ayuntamientos como Corporaciones representativas que son (artículo 140 de la Constitución), pueden, ciertamente, hacer realidad, mediante sus Acuerdos, la autodisposición en el establecimiento de los deberes tributarios, que es uno de los principios que late en la formación histórica - y en el reconocimiento actual, en nuestro ordenamiento - de la regla según la cual deben ser los representantes quienes establezcan los elementos esenciales para la determinación de la obligación tributaria» (STC 19/1987, F.J. 4)».

Tal y como se ha manifestado, «lo que diferencia a la ley del reglamento, y lo que fundamenta la reserva de ley, es una cierta calidad procedimental, ya que el procedimiento de aprobación de la ley, a diferencia del reglamentario, se sujeta a principios de publicidad y pluralidad en garantía de la intervención de las fuerzas políticas minoritarias»; y «no es posible ignorar que esa especificidad procedimental está asimismo presente en la aprobación

\footnotetext{
${ }_{29}$ Ahora bien, el Tribunal Constitucional reconoce en esta Sentencia 19/1987, de 17 de febrero, que a él no le corresponde «señalar positivamente cuáles sean los posibles modos de ajuste legislativo entre la autonomía municipal y la determinación por ley de los elementos esenciales de cada tributo», sino únicamente apreciar cuándo ese ajuste o equilibrio ha desaparecido por completo.

${ }^{30}$ SSTC 19/1987, F.J. 5 , 221/1992, F.J. $8^{\circ}$, y 233/1999, F.J. $10^{\circ}$

31 A este componente democrático se ha referido también el Tribunal Supremo en su Sentencia de 3 de febrero de 1987, señalando que «no puede desconocerse en los municipios la existencia de un cierto «componente político» que le viene atribuido a la Corporación por el origen democrático de sus componentes, que son elegidos por sufragio universal, libre, secreto y directo en la forma establecida por la ley y que tienen como misión fundamental el gobierno y la administración del municipio, siendo precisamente este componente político el motor de la vida municipal y cuyo respeto en cierta manera garantiza la Constitución».
} 
PODER TRIBUTARIO LOCAL Y RESERVA DE LEY ANTE LA PRÓXIMA REFORMA...

de sus normas por las asambleas locales» ${ }^{32}$, garantizándose así que la regulación de los tributos va a depender de la exclusiva voluntad de los ciudadanos expresada a través de sus representantes.

En consecuencia, no hay razones para plantear respecto a las normas reglamentarias locales, la sospecha de una ausencia o defecto de carácter democrático, como sí sucede con las disposiciones reglamentarias estatales. Ahora bien, este carácter representativo sólo es predicable del Pleno, no de la Comisión de Gobierno (en la actualidad, Junta de Gobierno Local conforme al art. 23 LBRL), de ahí que el Tribunal Constitucional en su Sentencia 233/ 1999 al enjuiciar la regulación que de los precios públicos se contenía en la Ley de Haciendas Locales de 1988, concluya que el Pleno sólo podrá delegar en la Comisión de Gobierno el establecimiento o modificación de precios públicos que no tengan la naturaleza de prestaciones patrimoniales de carácter público, «dado que este último órgano municipal, al no ser representativo (conforme al art. 23 de la LBRL se integra por el Alcalde y un número de Concejales no superior al tercio legal de los mismos, nombrados y separados libremente por aquél), no satisface plenamente la función garantista de la reserva de ley ex artículo 31.3 CE» (STC 233/1999, F.J. 18).

Como consecuencia de lo anterior, esto es, en virtud de la autonomía de los Entes locales constitucionalmente garantizada (art. $137 \mathrm{CE}$ ) y que el Tribunal Constitucional llega incluso a equiparar a la autonomía de las Comunidades Autónomas proclamada en el art. 156 CE (STC 168/2004, de 6 de octubre, F.J. 4), y del carácter representativo del Pleno de la Corporación municipal «es preciso que la ley estatal atribuya a los Acuerdos dictados por éste (... acuerdos dimanantes del ejercicio de la potestad de ordenanza), un cierto ámbito de decisión acerca de los tributos propios del Municipio, entre los cuales se encuentran las tasas» ${ }^{33}$. Ahora bien, esto no significa, como se apresura a advertir inmediatamente el Tribunal Constitucional, que «este ámbito de libre decisión de los Entes locales... no está exento de límites» ${ }^{34}$;

\footnotetext{
32 Aníbarro PÉREZ, S.: «Las competencias normativas de las Corporaciones Locales...», cit., pp. 53 y 54.

${ }^{33}$ Las normas reglamentarias fruto del ejercicio de las competencias normativas que en materia tributaria se atribuyen a los Entes locales encuentran su fundamento no en la Ley, sino que, como hemos visto, éste deriva, implícita (principio de autonomía local) o expresamente (art. 133) del texto constitucional.
}

\footnotetext{
${ }^{34}$ STC 233/1999, F.J. 10. Ha sido precisamente esta jurisprudencia sobre los límites dentro de los cuales debe quedar circunscrito el poder tributario local para salvaguardar el principio de reserva de ley, la que ha condicionado en gran medida al legislador, como reconoce ANíBARRo PÉREZ («Las competencias normativas de las Corporaciones locales...», cit., p. 63), y como comprobaremos al analizar a qué han quedado reducidas las competencias normativas de las Corporaciones locales a la luz del actual TRLHL. Es cierto que en los últimos años se han llevado a cabo una serie de modificaciones normativas que tenían como objetivo, entre otros, ampliar el ámbito de autonomía local, y más exactamente, incrementar el ámbito de decisión normativa de tales Entes; pero los resultados aún son insuficientes, ante las enormes expectativas existentes. De ahí que en la futura reordenación del Gobierno y la Administración local se persiga, como uno de los objetivos prioritarios, avanzar más en el camino reforzando las potestades normativas de las Entidades locales en general, y como lógica consecuencia, la específicamente tributaria.
} 
lo cual resulta obvio, si se recuerda el carácter derivado del poder tributario de las Corporaciones locales y la naturaleza necesariamente limitada de la autonomía local. Además, si la garantía de autoimposición fuese el único fundamento del principio de reserva de ley, carecería de justificación alguna su vigencia también en relación con las Corporaciones locales, cuyos Plenos gozan de un grado de representatividad democrática idéntico al de las Cortes Generales o al de los Parlamentos de las Comunidades Autónomas, como acaba de reconocer el Tribunal Constitucional; y si pese a lo anterior, la necesidad de la ley se mantiene en este ámbito local, se evidencia que existe una motivación adicional en la consagración constitucional de este principio, o si se prefiere, que encuentra su fundamento no sólo ni exclusivamente en la necesaria salvaguarda de la voluntad general ${ }^{35}$.

Por tanto, aunque los Acuerdos aprobados por el Pleno de la Corporación municipal garantizan la necesidad de autoimposición en el establecimiento de los deberes tributarios que late en la reserva de ley tributaria, sin que pueda oponerse desde esta perspectiva, reparo alguno; es claro que la reserva legal en esta materia existe también al servicio de otros principios esenciales, como son la preservación de una básica igualdad de posición de todos los contribuyentes y de la unidad del ordenamiento, que actúan como legítimo contrapeso de la particularidad territorial ${ }^{36}$; lo cual impide que el acuerdo municipal pueda sustituir por completo a la Ley.

Ello no significa que se imponga una uniformidad absoluta y, en consecuencia, que la diferente presión fiscal a la que puedan verse sometidos los ciudadanos por razón de territorio, suponga una vulneración del principio constitucional de igualdad ${ }^{37}$; de este modo, se ha afirmado que la igualdad no puede jugar en un plano intermunicipal, pues sólo tiene sentido lógico su exigencia ante un sistema tributario concreto ${ }^{38}$. Al respecto, el Tribunal Supremo en su Sentencia de 4 de octubre de 1984 ya reconoció que «cada municipio en uso de su autonomía constitucionalmente establecida y dentro de los límites que la ley permita podrá establecer tributos a los residentes en su territorio, sin que necesariamente tenga que resultar una tributación igual en todos los municipios lo que sería contrario tanto al principio de

\footnotetext{
35 Cubero Truyo, A.M.: op. cit., pp. 220 y 221.

${ }^{36}$ STC 19/1987, F.J. 4, y STC 233/1999, F.J. 10.

${ }^{37}$ MenÉndez Moreno, A.: «Algunas reflexiones sobre los principios de capacidad y legalidad...», cit., p. 31 .

${ }^{38}$ Esta es la opinión de CALvo OrTEGA, quien excluye que la igualdad pueda jugar en un plano intermunicipal, por diversas razones: de un lado, «porque la diversidad es consecuencia de la autonomía financiera, y por ello tributaria, concedida a los municipios y que tienen en nuestro ordenamiento rango constitucional», y de otro, porque «la política de servicios que fije cada corporación puede demandar una financiación cuantitativa y cualitativamente diversa»; y en consecuencia, «dada la vinculación existente entre Poder tributario y Poder presupuestario (ingreso y gasto público) sólo tiene sentido lógico la exigencia de la igualdad ante un sistema tributario concreto, que es lo mismo que decir ante un Poder fiscal determinado» («Principios tributarios»... cit., p. 52).
} 
PODER TRIBUTARIO LOCAL Y RESERVA DE LEY ANTE LA PRÓXIMA REFORMA...

adecuar la imposición a la necesidad de satisfacer los gastos, como a la justicia distributiva dadas las diferencias existentes a este respecto entre los municipios».

Por otra parte, respecto de los tributos propios de los municipios, la reserva de ley ni «deberá extenderse hasta un punto tal en que se prive a los mismos de cualquier intervención en la ordenación del tributo o en su exigencia para el propio ámbito territorial», ni «tampoco podrá el legislador abdicar de toda regulación directa en el ámbito parcial que así le reserva la Constitución (art. 133.1 y 2)... Las leyes reclamadas por la Constitución en su art. 133.2 no son, por lo que a las Corporaciones locales se refiere, meramente habilitadoras para el ejercicio de una potestad tributaria que originariamente sólo corresponde al Estado; son también Leyes ordenadoras -siquiera de modo parcial...- de los tributos así calificados de «locales», porque la Constitución encomienda aquí al legislador no sólo el reconocer un ámbito de autonomía al ente territorial, sino también garantizar la reserva legal que ella misma establece (art. 31.3)». En fin, lo que el legislador no puede hacer es renunciar «al establecimiento de toda limitación en el ejercicio de la potestad tributaria de las Corporaciones locales» ${ }^{39}$.

Por tanto, a raíz de estos pronunciamientos se puede concluir la necesidad de que se produzca una flexibilización, modulación o restricción de las exigencias de la reserva de ley cuando de la capacidad de normación de los Entes locales en materia tributaria se trata ${ }^{40}$; esta necesaria modulación ya había sido demandada reiteradamente desde instancias doctrinales ${ }^{41}$ y se ha visto confirmada, como acabamos de ver, en diversas sentencias del Tribunal Constitucional; quien, sin embargo, continúa manteniendo una posición bastante conservadora, restringiendo o reduciendo las posibilidades reales que se derivarían de su posición, si se llevase hasta sus últimas consecuencias ${ }^{42}$. Evidentemente, no debiera hablarse de flexibilización del principio de reserva de ley, cuando la potestad normativa municipal se ejerza en relación a las competencias propias de los Entes locales.

El principal problema se encuentra en determinar cuál ha de ser el grado de modulación que ha de producirse, o si se prefiere, el límite hasta el que han

\footnotetext{
39 STC 19/1987, F.J. 4, y STC 233/1999, F.J. 10.

${ }^{40}$ Calificamos esta modulación de la reserva de ley cuando se proyecta sobre el ámbito local como necesaria, pues como se reconoce en el Libro Blanco para la Reforma del Gobierno Local en España «una concepción extensiva de la reserva de ley degradaría la autonomía local a mera ejecución discrecional de la ley ignorando su naturaleza política y el derecho del gobierno local a disponer, bajo la propia responsabilidad, de una parte importante de los asuntos públicos decidiendo entre varias opciones políticas».

${ }^{41}$ Esta idea de flexibilización y modulación del principio de reserva de Ley, al confrontarlo con el principio de autonomía local, ha sido defendida por CALVo ORTEGA, R.: «Principios tributarios...», cit., p. 69, y del mismo autor, «Las Ordenanzas fiscales», en La Reforma de las Haciendas Locales, Tomo I, Lex Nova, Valladolid, 1991, p. 88; LozAno SERrano, C.: «Potestades tributarias...», cit., p. 28; RAMALlO Massanet, J., y Zornoza PÉrez, J.: «Autonomía y suficiencia financiera...», cit., p. 508; y ANíBARro PÉREZ, S.: «Las competencias normativas de las Corporaciones Locales...», cit., p. 61, entre otros.
} 
de reducirse las exigencias derivadas del principio de reserva de ley; habiéndose propuesto, al respecto, la utilización, como referente o criterio rector, de técnicas tradicionales de cooperación en el ejercicio de la potestad normativa, como puedan ser la relación entre ley básica y leyes autonómicas de desarrollo ${ }^{43}$. Este límite, difícil de determinar a priori y en abstracto con precisión, podría ubicarse en lo que tradicionalmente se ha considerado como «contenido mínimo o esencial» de la reserva de ley; y que tratándose de los tributos locales, ha de interpretarse como un contenido máximo. En este sentido, la intervención de la Ley ha de cubrir márgenes mínimos, y no máximos, cuando de la regulación de los tributos locales se trata, propiciando e incentivando la necesaria, y deseable, colaboración y participación de la norma local ${ }^{44}$.

Una vez establecido el tributo local en el sentido de creación ex novo, y regulados sus elementos materiales y formales esenciales por una norma de rango legal; podrá la Entidad local integrar esta normación, no sólo como resulta evidente en relación a los restantes aspectos del tributo no cubiertos por la reserva, sino también en sus propios elementos esenciales, dentro del marco prefijado por la norma legal. De este modo, vemos cómo esa especial modulación se traduce, en esencia, en la posibilidad de que la norma local colabore con la Ley en la configuración de la materia inicialmente reservada a la misma ${ }^{45}$; propiciándose así que, incluso respecto del establecimiento y regulación de los elementos esenciales del tributo en su perspectiva material y formal, se produzca una cierta intervención de la Corporación local ${ }^{46}$.

\section{C) Las ordenanzas fiscales como manifestación del poder tributario local}

Las Ordenanzas y Reglamentos municipales constituyen una fuente de Derecho y una manifestación de autonomía, y como tales manifestaciones de autonomía, la contemplación de su contenido potencial y su proceso de elaboración informa, a la vez, del grado de libertad y de control de la vida municipal, así como de la cuantía o alcance de sus competencias ${ }^{47}$.

\footnotetext{
${ }^{42}$ Crítica efectuada por Aníbarro Pérez, S.: «Las competencias normativas de las Corporaciones Locales...», cit., p. 61 .

43 Ibid., p. 55.

${ }^{44}$ En este sentido, se ha sostenido que aquello que en todo lugar ha de regularse siempre por una norma legal es el hecho imponible del tributo en cuestión, siendo posible la reglamentación por la propia Corporación local del resto de elementos del tributo. Ésta viene a ser la opinión de MENÉNDEZ MoRENO, A.: «El poder tributario de las Corporaciones locales», cit., p. 2122; e insiste en esta idea en «Algunas reflexiones sobre los principios de capacidad y legalidad...», cit., pp. 30 y 31 .

45 Aníbarro PÉRez, S.: «Las competencias normativas de las Corporaciones locales...», cit., p. 61.

${ }^{46}$ En parecidos términos se han pronunciado Ramallo Massanet, J., y Zornoza Pérez, J.: «Autonomía y suficiencia financiera...», cit., pp. 507 y 508.

${ }^{47}$ Embid Irujo, A.: «La potestad reglamentaria de las Corporaciones locales», en Organización territorial del Estado (Administración local), Volumen II, IEF, Madrid, 1985, pp. 985 у 986.
} 
PODER TRIBUTARIO LOCAL Y RESERVA DE LEY ANTE LA PRÓXIMA REFORMA...

La voluntad del Pleno de la Corporación que satisface, como hemos visto, las exigencias del principio democrático o de autoimposición, se plasma jurídicamente en materia tributaria, por medio de Ordenanzas. Son normas jurídicas de valor y fuerza reglamentarios, fruto de la atribución que de la potestad reglamentaria se realiza a las Corporaciones locales, de manera implícita en el art. 140 CE, y expresamente por los arts. 4 y 106 LBRL y los arts. 15 a 19 TRLHL ${ }^{48}$; y que han sido consideradas, tradicionalmente, como una manifestación o expresión de la autonomía tributaria municipal. El art. 7.1. e) LGT las cita como fuentes del ordenamiento tributario y se definen en el Borrador de Anteproyecto de Ley Básica del Gobierno local como aquellas «disposiciones normativas aprobadas por acuerdo del Pleno de la Asamblea correspondiente que regulan los servicios, actividades, la hacienda y los ingresos de las entidades locales» (art. 25.3) ${ }^{49}$.

De las consideraciones realizadas por el Tribunal Constitucional en su Sentencia 233/1999, de 16 de diciembre, en la que expresamente afirma que el ámbito de libre decisión dejado a las Corporaciones locales es «desde luego mayor que el que pudiera relegarse a la normativa reglamentaria estatal»; puede deducirse el reconocimiento a estas Ordenanzas fiscales de un alcance superior y distinto al de meras normas reglamentarias, alcance que permitiría calificarlas como «normas suprarreglamentarias» ${ }^{50}$.

En efecto, el Tribunal Constitucional viene a decir que las normas reglamentarias locales ocupan una posición diversa en el ordenamiento jurídico tributario a la que puedan tener los reglamentos estatales o autonómicos ${ }^{51}$. No pueden asimilarse y equipararse sin más, pese a que todas compartan un mismo rango, dado que entre ellas existe una diferencia que resulta ser sustancial; no se puede olvidar que los Reglamentos y Ordenanzas locales proceden, al igual que la Ley, de un órgano o institución esencialmente democrática y representativa, que garantiza que los tributos sean establecidos y aprobados por los representantes de aquellos que están llamados a soportar-

\footnotetext{
48 Calvo Ortega, R.: «Las Ordenanzas fiscales», cit., p. 87.

49 Uno de los objetivos que se persigue con el nuevo texto básico es reforzar las potestades, especialmente la normativa y sancionadora, de los Entes locales con el propósito de corregir las dificultades derivadas, entre otros, del principio de reserva de ley. Con este objetivo se dedica un precepto específico a la potestad normativa de dichos Entes, que comienza reconociendo que «en la esfera de sus competencias, las entidades locales aprueban sus Estatutos, las Ordenanzas y los Decretos de organización y los de emergencia, que en ningún caso contendrán preceptos opuestos a las leyes»; y seguidamente se definen cada una de estas disposiciones normativas locales.

${ }^{50}$ Rubio de Urquía, J.I.: «Alcance de la potestad normativa de las Entidades locales en materia de gestión tributaria: algunas puntualizaciones», Tributos locales, n. ${ }^{\circ}$ 7, 2001, p. 96.

51 Así ha sido reconocido también por Aníbarro Pérez, S.: «Las competencias normativas de las Corporaciones locales...», cit., ps. 53 y 62; Arnal Suría, S. y González Pueyo, J.: Manual de Ingresos de las Corporaciones locales, El Consultor de los Ayuntamientos y de los Juzgados, Madrid, 2001, pp. 83 a 85, entre otros autores; así como se infiere de algunas decisiones judiciales como la STSJ de Extremadura de 22 de enero de 1996, en la que se reconoce expresamente que la colaboración Ley-Reglamento en el ámbito local alcanza perfiles singulares.
} 
los. Es aquí donde reside, por tanto, la verdadera especificidad de las normas tributarias locales, y es este rasgo característico el que justifica que en el ámbito local se postule una restricción o debilitamiento de las exigencias del principio de reserva de ley.

En consecuencia, la expresión «con arreglo a la ley» utilizada por el artículo 31.3 de la Constitución, ha de interpretarse de forma distinta cuando se aplica a las Ordenanzas municipales o se refiere a los Reglamentos estatales o autonómicos; como reconoció la Sentencia del TSJ de Extremadura de 22 de enero de 1996, en la que se declaró que «la colaboración Ley y Reglamento en el ámbito local alcanza unos perfiles singulares», y que «el principio de reserva de ley no puede llegar a convertirse en un impedimento para que los Ayuntamientos intervengan de alguna forma en el diseño de su propia Hacienda»; siendo «voluntad del constituyente que los Ayuntamientos puedan producir normas en aspectos que les afectan sustancialmente, conclusión que resulta avalada por la propia finalidad de la Ley 39/1998, de 28 de diciembre, y que, como dice su exposición de motivos, no es otra que, amén de racionalizar el sistema financiero y tributario de las Haciendas locales, hacer efectivos hasta los mayores límites posibles los principios de autonomía y suficiencia financiera permitiéndoles incidir en la determinación del volumen de sus recursos».

Todo ello hace que este principio suavice sus exigencias cuando articula las relaciones Ley-Reglamento local, y no cuando opera en el ámbito LeyReglamento estatal; y una muestra significativa de lo que venimos afirmando la constituye, el distinto razonamiento realizado por el Tribunal Constitucional, al enjuiciar la regulación que de los llamados precios públicos se contenía en la Ley 8/1989, de 13 de abril, de Tasas y Precios Públicos y en la Ley 39/1988, de 28 de diciembre, reguladora de las Haciendas Locales, en sus Sentencias 185/1995, de 14 de diciembre, y 233/1999, de 16 de diciembre, respectivamente ${ }^{52}$. Al referirse a la normativa específica local, reconoce que «no es posible trasladar a este lugar sin las precisas matizaciones la doctrina que sobre la reserva de ley reflejamos en el fundamento jurídico 6 de la STC 185/1995, sino que ésta debe circunscribirse al concreto y espe-

\footnotetext{
${ }^{52}$ En la STC 233/1999, tras precisar que el concepto de precio público contenido en la LRHL no transgrede por sí mismo la Constitución [F.J. 16], declara la constitucionalidad del primer inciso del art. 48.1 LHL, en el que se atribuye al Pleno de la Corporación la competencia para establecer o modificar los precios públicos [F.J. 18], lo que se considera inconstitucional es la delegación que el Pleno de la Corporación pueda hacer en la Comisión de Gobierno (hoy, Junta de Gobierno Local) para establecer la totalidad de los precios públicos que recogía el art. 41 de la LHL, en atención a un argumento de déficit representativo o democrático (no «satisface plenamente la función garantista de la reserva de ley ex artículo 31.3 CE», F.J. 18). Esta inconstitucionalidad queda salvada, precisa el Tribunal, siempre que el «Pleno de la corporación establezca o apruebe mediante Ordenanza los precios que constituyan prestaciones patrimoniales de carácter público, quien podrá delegar únicamente en la Comisión de Gobierno el establecimiento o modificación de los que no tienen naturaleza de prestaciones patrimoniales de carácter público». Al respecto puede consultarse FERnández PAVÉs, M.J.: «Sistema de financiación local: las tasas tras la Sentencia del Tribunal Constitucional de 1999 sobre la Ley de haciendas Locales»; Revista de Estudios Locales, CUNAL, nº extra de 2000.
} 
PODER TRIBUTARIO LOCAL Y RESERVA DE LEY ANTE LA PRÓXIMA REFORMA...

cífico ámbito para el que se dictó. Hay que recordar, en efecto, que en la STC 185/1995 enjuiciamos la sintonía con la reserva de ley tributaria de prestaciones patrimoniales de carácter público de ámbito estatal. Aquí, sin embargo, debemos decidir sobre la constitucionalidad desde la perspectiva de los artículos 31.3 y $133 \mathrm{CE}$ de uno de los tributos que integran la $\mathrm{Ha}$ cienda de las Entidades locales. Y la descrita es una peculiaridad de la que, como hemos señalado en ocasiones anteriores, derivan necesariamente consecuencias respecto de la reserva de ley tributaria» (STC 233/1999, F.J. 10).

Además, en la relación Ley-Reglamento local en materias en las que las Corporaciones locales tienen reconocidas competencias normativas, «la ley sí encuentra un límite infranqueable, en tanto en cuanto no podrá agotar toda la regulación, ya que de hacerlo estaría invadiendo el ámbito de autonomía local constitucionalmente protegido» ${ }^{53}$; mientras que en la relación Ley-Reglamento estatal la ley no encuentra ningún límite. Atendiendo a ello se ha llegado a criticar a nivel doctrinal, la producción reglamentaria del Gobierno en materia tributaria local; e incluso, a defender la no existencia de normas reglamentarias, bien sea estatales o autonómicas, entre la Ley estatal que ordena los aspectos básicos y esenciales del régimen jurídico material y formal de los tributos locales y las normas reglamentarias locales ${ }^{54}$.

\section{CONFIGURACIÓN DEL PODER TRIBUTARIO LOCAL EN LAS LEYES ORDINARIAS}

Vista la posición del Tribunal Constitucional sobre la especial operatividad del principio de reserva de ley en materia tributaria local, y las consecuencias que de su doctrina se derivan; vamos a analizar cómo se ha configurado por la normativa este ámbito de poder normativo local. Sin duda, la determinación del margen de decisión que se quiera otorgar a los Entes locales en el ámbito de sus tributos propios es una opción política; correspondiendo al legislador la concreción del grado de intervención normativa de que han de gozar dichos Entes, respetando siempre, evidentemente, el mínimo garantizado por la Constitución ${ }^{55}$. El legislador, al adoptar esta decisión, ha estado directamente mediatizado por la interpretación que el Tribunal Constitucional ha realizado sobre el poder normativo de las Entidades locales en materia tributaria, al interrelacionar los principios de autonomía y reserva de ley, si bien, en ocasiones de manera más agudizada que el Tribunal Constitucional, mantiene una posición bastante conservadora y restrictiva en cuanto al alcance y extensión de dicho poder.

\footnotetext{
${ }^{53}$ ANíbarro PÉReZ, S.: «Las competencias normativas de las Corporaciones locales...», cit., p. 54.

${ }_{54}$ Éste es el parecer de CAlvo Ortega, R.: «Las Ordenanzas fiscales», cit., pp. 75, 76 y 88.

${ }^{55}$ En parecidos términos se pronuncia ANíbarro Pérez, S.: «Las competencias normativas de las Corporaciones locales...», cit., p. 66.
} 
La Ley 7/1985, de 2 de abril, reguladora de las Bases del Régimen Local constituye un primer paso en el proceso de definición y delimitación del poder tributario local; reconoce expresamente a Municipios, Provincias e Islas (los llamados, entes locales necesarios) su potestad tributaria y financiera, junto a la reglamentaria y de autoorganización (art. 4.1.b) y a), respectivamente) ${ }^{56}$; potestades propias que ejercerán «en régimen de autonomía y bajo la propia responsabilidad, atendiendo siempre a la debida coordinación en su programación y ejecución con las demás Administraciones públicas» (art. 7.2). Insiste en esta idea el apartado 1 del art. 106 de este mismo texto normativo, en el que, en términos parecidos a los del art. 133.2 $\mathrm{CE}^{57}$, se especifica que «las Entidades locales tendrán autonomía para establecer y exigir tributos de acuerdo con lo previsto en la legislación del Estado reguladora de las Haciendas locales y en las Leyes que dicten las Comunidades Autónomas en los supuestos expresamente previstos en aquélla» ${ }^{58}$. Se remite, por tanto, para conocer el alcance de las competencias normativas de que gozarán las Entidades locales respecto del establecimiento y exigibilidad de sus tributos propios, a lo establecido en la Ley reguladora de las Haciendas Locales.

El Real Decreto Legislativo 2/2004, de 5 de marzo, por el que se aprueba el Texto refundido de la Ley reguladora de las Haciendas Locales (en adelante, TRLHL), que no dedica ningún precepto a reconocer en general o en abstracto el poder tributario local ${ }^{59}$, delimita las competencias normativas que tendrán los Entes locales respecto de sus tributos propios básicamente en los arts. 15 y 59 de dicho texto normativo. De la conjunción de estos dos preceptos se derivan los límites legales impuestos al ejercicio de dicho poder normativo tributario local. Estos límites están en función de la concreta figura tributaria de que se trate (impuestos, tasas y contribuciones especia-

\footnotetext{
${ }^{56}$ También el art. 4 LGT hace una mención expresa al poder tributario (potestad, dice la norma) de las Entidades locales, que no añade nada a lo ya establecido en la Constitución y en la LBRL; en particular, señala que «las Comunidades Autónomas y las Entidades Locales podrán establecer y exigir tributos, de acuerdo con la Constitución y las leyes» (apartado 2).

57 No obstante, se ha de indicar que existe una diferencia de formulación esencial entre el art. 133.2 de la CE y el art. 106.1 de la LBRL, pues en el precepto constitucional se reconoce la potestad de los Entes locales para establecer y exigir tributos en el marco de la Constitución y las leyes, y en el precepto de la LRBRL se concreta dicho marco en dos sentidos; de un lado, se refiere a la legislación del Estado reguladora de las Haciendas locales, y de otro, a las leyes de las Comunidades Autónomas (Vid. Lozano Serrano, C.: «Potestades tributarias....», cit., p. 11). Por su parte, Rubio De Urquía ha señalado que la diferencia esencial entre una y otra formulación es que «mientras que la primera (el art. 133.2 CE) vincula el poder tributario de las Entidades locales al principio de autonomía, la segunda (el art. 106.1 LRBRL) no recoge, en absoluto, tal vinculación» («Las competencias de las Entidades locales en la Gestión tributaria. Delegación de competencias. Colaboración interadministrativa en la Gestión Fiscal», en La Gestión tributaria en la Hacienda Local, CEMCI, Instituto Nacional de la Administración Pública, Granada, 1991, p. 21).

${ }^{58}$ Llama la atención que en el Borrador de Anteproyecto de Ley Básica del Gobierno y de la Administración local se haya suprimido la referencia y regulación básica de la Hacienda local, que sí contiene la actual LBRL.
}

${ }^{59}$ Lozano Serrano, C.: «Potestades tributarias....», cit., p. 23. 
PODER TRIBUTARIO LOCAL Y RESERVA DE LEY ANTE LA PRÓXIMA REFORMA...

les), y en el caso concreto de los impuestos, dependiendo de su naturaleza potestativa u obligatoria.

En efecto, el ámbito de intervención normativa dejada a las Entidades locales es mayor cuando se trata de tasas y contribuciones especiales, pues la Ley se limita en estos casos a regular únicamente sus aspectos definidores; dejando un amplio margen de decisión a las Entidades locales. Dicho margen se reduce considerablemente cuando de impuestos se trata. Sus competencias normativas en esta materia difieren según se trate de impuestos potestativos u obligatorios. En el primer caso, las Entidades locales gozan de plena libertad para decidir su establecimiento y exacción, o no; y en el caso de que decidan exigirlos, deberán acordar su imposición (art. 15.1 TRLHL). Asimismo, podrán modular algunos aspectos de los elementos de cuantificación, así como, regular determinados aspectos y acordar la concesión de beneficios fiscales. Por su parte, en los impuestos de exacción obligatoria, carecen las entidades municipales de capacidad para decidir su establecimiento y exacción, de modo que no es necesario acuerdo de imposición; su ámbito de decisión se reduce en esencia, al igual que en el caso anterior, a fijar algunos elementos que inciden en la determinación de la cuota tributaria, así como, en el reconocimiento y aplicación de beneficios fiscales, fundamentalmente.

Resulta, por tanto, que la autonomía local se manifiesta ${ }^{60}$, de un lado, mediante la atribución de tributos de establecimiento discrecional (en teoría); respecto de los cuales se permite al Ente local decidir si los exige o no, aunque en el supuesto de que decida establecerlos, apenas si dispondrá de capacidad para modularlos dada la minuciosidad con que la ley los configura, en ocasiones de manera excesiva (llegando incluso a fijar el plazo de presentación de la correspondiente declaración o autoliquidación, como sucede en el IIVTNU en el art. 110.2 TRLHL) ${ }^{61}$. Y de otro lado, en la posibilidad de modificar o incidir en algunos elementos de cuantificación mediante la fijación del tipo de gravamen, la tarifa o el coeficiente, básicamente ${ }^{62}$, y de regular el establecimiento y requisitos exigidos para la concesión o no de algunos beneficios fiscales ${ }^{63}$.

\footnotetext{
${ }^{60}$ Fernández Pavés, M.J.: «La reforma de las haciendas Locales», Modificaciones y panorama actual del Régimen Local Español; CEMCI, Granada, 2000, ps. 478 y ss.

${ }^{61}$ Podrá acordar o no, por tanto, el Ente local la exigencia de las tasas, contribuciones especiales, ICIO, IIVTNU e Impuesto sobre Gastos Suntuarios (art. 15.1 TRLHL).

${ }^{62}$ Podrá el Ente local acordar los tipos de gravamen en el IBI, ICIO e IIVTNU, incidir sobre la cuota de Tarifa del IAE mediante la aplicación de determinados índices, incrementar o no las cuotas del IVTM, incidir sobre la base tributaria del IIVTNU, etc.

${ }^{63}$ En materia de beneficios fiscales se amplió el margen de intervención de las Entidades locales a partir de la modificación del art. 9 de la LRHL por la Ley 50/1998, de 30 de diciembre, de Medidas Fiscales, Administrativas y del Orden Social. Sin dejar de ser necesario en todo caso que las exenciones y demás beneficios fiscales de los tributos locales se establezcan en normas con rango de ley, se contempló expresamente que «también podrán reconocerse los beneficios fiscales que las Entidades locales
} 
También en el ámbito estrictamente formal del tributo, el alcance del poder normativo de las Entidades locales ha sido excesivamente reducido; de un lado, porque el texto legal contiene con relación a cada impuesto, y para las tasas y contribuciones especiales en general, algunas menciones explícitas a particularidades de su procedimiento de gestión; y de otro, porque hasta la aprobación de la actual LGT, ha operado como un límite importante en la normación por parte de los Entes locales del procedimiento de aplicación de sus propios tributos, la remisión genérica que el art. 12 LRHL (en la actualidad, mantiene el tenor que tenía desde su redacción por la Ley 50/1998, de 30 de diciembre, de Medidas Fiscales, Administrativas y del Orden Social) realiza en esta materia a la LGT y demás disposiciones normativas de desarrollo aprobadas por el Estado ${ }^{64}$.

Nos encontramos, por tanto, ante una ley a la que se había tachado o calificado como bastante exhaustiva y excesivamente reglamentaria ${ }^{65}$; notas definitorias que mantiene en la actualidad, pues deja un escaso margen de intervención en la normación de sus tributos propios y de su procedimiento de exacción a los Entes locales. En su texto se reducen casi al mínimo posible las competencias normativas de estos Entes en la regulación de sus tributos, y para ello, el legislador estatal se escuda, no en el principio de reserva de ley, respecto del cual hemos visto que al confrontarlo con la autonomía local, sufre una modulación o flexibilización que permite reducir sus exigencias, siendo necesario que ajuste su intervención a estándares mínimos; sino en la competencia exclusiva del Estado sobre el sistema tributario estatal, proclamada en el art. 133.1 CE. Dicho en otros términos, la extensión de regulación de esta ley y su potencialidad de producción reglamentaria ${ }^{66}$, es de tal amplitud, que incide sobre aspectos o elementos normalmente no cubiertos por la reserva de ley; esto es, existen aspectos que quedan claramente fuera del ámbito de protección de este principio, y que, sin

\footnotetext{
establezcan en sus ordenanzas fiscales en los supuestos expresamente previstos en la Ley»; lo que va a «suponer un notable incremento del poder tributario de las Corporaciones locales», aunque en ningún caso éstas «podrán crear exenciones ex novo, sino que su labor consistirá en integrar o, lo que es igual, completar, por medio de las ordenanzas fiscales las contempladas en la Ley», en palabras de VEGA Herrero, M.: «La intervención de los Municipios en las exenciones de sus tributos», en Estudios de Derecho Financiero y Tributario en homenaje al Profesor Calvo Ortega, Tomo II, Lex Nova, Valladolid, 2005, pp. 2168 y 2170.

${ }^{64}$ Véase al respecto las consideraciones realizadas en nuestro trabajo JABALERA RodríGUEZ, A.: La gestión impositiva municipal en la nueva L.G.T., Marcial Pons, Madrid, 2005.

${ }^{65}$ Crítica efectuada por Calvo Ortega, R.: «Las Ordenanzas fiscales», cit., p. 89; Lozano Serrano, C.: «Potestades tributarias...», cit., ps. 19 y 20; Ramallo Masanet, J.. y Zornoza Pérez, J.: «Autonomía y suficiencia financiera...», cit., p. 508.

${ }^{66}$ Potencialidad de producción reglamentaria que se manifiesta, por ejemplo, en la Disposición Final Única de este TRLHL, que autoriza al Gobierno de la Nación para dictar cuantas disposiciones sean necesarias para el desarrollo y ejecución de esta Ley. De este modo, se constriñe el espacio que en principio podría entenderse reservado a la producción normativa de las Corporaciones locales; y se constata, tal y como ha señalado CALvo ORTEGA, al comentar su redacción que coincide casi literalmente en la LRHL, la invasión de la zona de autonomía tributaria por normas estatales que no realizan el principio de reserva de ley («Principios tributarios...», cit., p. 78).
} 
PODER TRIBUTARIO LOCAL Y RESERVA DE LEY ANTE LA PRÓXIMA REFORMA...

embargo, han sido detenidamente regulados ${ }^{67}$. En este sentido se ha llegado incluso a afirmar que la LRHL es un claro ejemplo de invasión del campo propio de intervención de las Ordenanzas fiscales ${ }^{68}$.

En definitiva, a pesar de las modificaciones producidas en los últimos años (Leyes 50/1998, de 30 de diciembre y 55/1999, de 26 de diciembre, ambas de Medidas Fiscales, Administrativas y del Orden Social, y la Ley 51/2002, de 27 de diciembre, de reforma de la Ley 39/1988, de 28 de diciembre, RHL, etc.) orientadas teóricamentea otorgar una mayor autonomía tributaria a las Corporaciones locales, y que han supuesto la atribución de mayores competencias normativas a tales entidades, fundamentalmente en materia de beneficios fiscales y en relación con algunos elementos de cuantificación del tributo; sigue siendo enormemente discutible y cuestionable el grado de precisión del TRLHL, y el escaso margen de actuación que deja a los Municipios en la regulación de sus tributos propios ${ }^{69}$; sobre todo, si se atiende a lo que podría resultar de la doctrina del Tribunal Constitucional, y de la interpretación de los principios de autonomía y reserva de ley, como hemos visto.

De todos modos, no se puede olvidar que esta opción, que en la actualidad recoge el TRLHL, el cual ha elegido la postura más prudente y segura ${ }^{70}$, compatibilizando las exigencias derivadas de la autonomía local con el entendimiento jurisprudencial de la reserva de ley tributaria en la articulación del poder tributario local; es una opción legítima (aunque discutible en nuestra opinión), que cuenta con el refrendo del Tribunal Constitucional, que mantiene al respecto una postura muy restrictiva y poco consecuente con sus propios planteamientos, y respetuosa con los estándares internacionales fijados en la propia Carta Europea de Autonomía Local ${ }^{71}$. En este texto internacional se dispone que, respecto de los tributos locales, ha de reconocerse a las Entidades locales la potestad de fijar la cuota o el tipo dentro de los límites de la Ley (art. 9.3 ${ }^{72}$ ); aunque, tal y como se ha reconocido, «el objetivo de

\footnotetext{
${ }^{67}$ En este sentido se manifiesta también Calvo Ortega, R.: «Las ordenanzas fiscales», cit., p. 89, y el mismo autor en «Principios tributarios...», cit., p. 79.

68 Calvo Ortega, R.: «Las Ordenanzas fiscales», cit., p. 89.

${ }^{69}$ En opinión de LOZANO SERRANO «siendo la realidad social diferenciada de cada municipio fundamento suficiente para admitir la diversidad de tipos de gravamen (STC 19/1987, de 17 de febrero), no se entiende que no lo sea también para permitir otras diversidades en la regulación de sus tributos. Aspectos que tanto inciden en la situación y necesidades locales como el tratarse de un municipio rural, de montaña, turístico o residencial, ciudad-dormitorio, dispersión o concentración de la población, y otros, no es que no se tengan en cuenta por la Ley; es que tampoco se podrán tener en cuenta por el propio ente al establecer sus impuestos propios» («Potestades tributarias...», cit., p. 29).

70 Ramallo Massanet, J., y Zornoza Pérez, J.: «Autonomía y suficiencia financiera...», cit. p. 508.

71 En este sentido se pronuncia ANíBARRo PÉREZ al analizar el margen de decisión con que cuentan las Corporaciones locales para la concreción del quantum de sus impuestos ( «Las competencias normativas de las Corporaciones locales...», cit., p. 66); e insiste esta autora en esta misma idea en «Los principios de autonomía y suficiencia...», cit., p. 104.

${ }^{72}$ Textualmente dice este precepto que «una parte al menos de los recursos financieros de las Entidades locales debe provenir de ingresos patrimoniales y de tributos locales respecto de los que tengan la potestad de fijar la cuota o el tipo dentro de los límites de la Ley».
} 
la Carta Europea no es fijar niveles máximos de autonomía local, sino más bien niveles o estándares mínimos por debajo de los cuales no sería posible hablar seriamente de entes dotados de autonomía» ${ }^{73}$.

\section{DESARROLLO DE LA LGT POR LOS REGLAMENTOS LOCALES}

Con carácter general, la actual LGT a grandes rasgos, sigue ignorando la realidad local y ello pese a su pretendida vocación totalizadora y universal, que manifiesta en su art. 1.1 al proclamar que «esta Ley establece los principios y las normas jurídicas generales del sistema tributario español y será de aplicación a todas las Administraciones tributarias en virtud y con el alcance que se deriva del artículo 149.1.1 ${ }^{a}, 8^{a}, 14^{a}$ y $18^{a}$ de la Constitución». No obstante, entre otras, se realizan tres menciones que consideramos de interés: de un lado, en el art. 7.1.e) se citan expresamente las Ordenanzas fiscales locales como fuente del ordenamiento tributario; en el art. 83.4 se alude a la autonomía organizativa de cada Administración tributaria, afirmándose que «corresponde a cada Administración tributaria determinar su estructura administrativa para el ejercicio de la aplicación de los tributos», que en el caso concreto de la Administración local tendrá su reflejo en su Reglamento orgánico. Y finalmente, la Disposición Adicional Cuarta, en la que se alude, como lógica consecuencia del reconocimiento de las Ordenanzas fiscales como fuente del ordenamiento tributario, a la posibilidad de desarrollo por las Entidades locales de lo dispuesto en la Ley General Tributaria.

En concreto, se establece en dicha Disposición Adicional que «las entidades locales, dentro del ámbito de sus competencias, podrán desarrollar lo dispuesto en esta Ley mediante la aprobación de las correspondientes ordenanzas fiscales» (apartado 3); alterándose, en cierto modo, el actual esquema de prelación de fuentes que rige en determinadas materias locales, y obligando a realizar una interpretación de algunos preceptos del TRLHL a la luz de esta nueva atribución normativa. Nos referimos en concreto a aquéllos en los que se realiza una remisión directa, no sólo a la normativa estatal de rango legal, sino también a las normas secundarias que la desarrollan; así sucede, entre otros supuestos, en el art. 12 TRLHL ${ }^{74}$.

\footnotetext{
73 Aníbarro PÉrez, S.: «Los principios de autonomía y suficiencia...», cit., p. 104.

${ }^{74}$ Igual sucede en el art. 11 del TRLHL en el que en materia de infracciones y sanciones tributarias en los tributos locales «se aplicará el régimen de infracciones y sanciones regulado en la Ley General Tributaria y en las disposiciones que la complementen y desarrollen [en la actualidad, el Real Decreto 2063/2004, de 15 de octubre, por el que se aprueba el Reglamento general del régimen sancionador tributario], con las especificaciones que resulten de esta ley y las que, en su caso, se establezcan en las Ordenanzas fiscales al amparo de la ley». Por su parte, en la exacción de estos tributos los recargos e intereses de demora se exigirán y determinarán «en los mismos casos, forma y cuantía que en la exacción de los tributos del Estado»; si bien, se prevé expresamente que la Ordenanza fiscal pueda contemplar, ordenar y regular la exención del pago del interés de demora en los acuerdos de aplazamiento o
} 
PODER TRIBUTARIO LOCAL Y RESERVA DE LEY ANTE LA PRÓXIMA REFORMA...

Recordemos que este último precepto dispone en su primer apartado que «la gestión, liquidación, inspección y recaudación de los tributos locales se realizará de acuerdo con lo prevenido en la Ley General Tributaria y en las demás Leyes del Estado reguladoras de la materia, así como en las disposiciones dictadas para su desarrollo» ${ }^{75}$. Sin duda, el aspecto más discutible de este primer apartado es que, del mismo, se puede inferir la aplicabilidad directa, no sólo de las normas legales estatales reguladoras de la aplicación de los tributos, en general, sino también de las disposiciones reglamentarias dictadas en desarrollo de dicha normativa. De este modo, parece situarlas en una posición de prevalencia y preeminencia respecto de las propias normas reglamentarias locales a las que, no podemos olvidar, el Tribunal Constitucional ha reconocido un plus de eficacia en base a su sustrato democrático (STC 233/1999, de 16 de diciembre, entre otras). Con dicha interpretación de esta disposición, se lograría reducir sobremanera el posible ámbito en el que la Entidad local podría hacer uso de sus competencias normativas para diseñar el procedimiento de aplicación y exacción de sus tributos propios, sin que exista una justificación suficiente para ello; ya que no encuentra su fundamento en el principio de reserva de ley, no conlleva una mayor salvaguarda de los principios de igualdad y unidad del ordenamiento, y supone evidentemente una merma significativa del principio de autonomía local, además de muy probablemente, de la eficacia y eficiencia administrativa local.

Esta situación creemos ha cambiado en gran medida a partir de la aprobación de la nueva LGT, y en concreto, atendiendo al tenor literal de su Disposición Adicional Cuarta (apartado 3) que hemos reproducido. En la actualidad, la remisión que realiza el 12.1 TRHL a «las disposiciones dictadas para su desarrollo», ha de ser necesariamente reinterpretada; en tanto que la propia Entidad local puede ordenar directamente el procedimiento de aplicación de sus tributos, siempre de conformidad a lo establecido en la LGT, sin estar vinculada a lo dispuesto en otras disposiciones de rango reglamentario dictadas en desarrollo de la misma. De este modo, junto a los reglamentos de gestión, inspección, recaudación, etc., que se dicten a nivel estatal desarrollando lo dispuesto en la LGT; podemos encontrarnos con reglamentos locales, Ordenanzas fiscales, tantos como Entidades locales decidan hacer uso de esta facultad que se les confiere, que cumplen ese mismo cometido, si bien reducen su eficacia al ámbito de cada una de esas entidades locales. De ello resulta, por tanto, que sólo cuando la Entidad local no regule mediante or-

fraccionamiento del pago en período voluntario relativos a tributos de cobro periódico mediante recibo devengados en ese mismo ejercicio (art. 10 TRLHL).

${ }^{75}$ No contiene el TRLHL una norma general relativa a la gestión, liquidación, inspección o recaudación de los tributos locales, sino que se limita a realizar una remisión en bloque a la legislación estatal existente sobre aplicación de los tributos. Tan sólo contempla el TRLHL algunas normas particulares de gestión específicamente referidas a cada uno de los tributos propios en particular, y que no han sido objeto de desarrollo reglamentario, salvo algunos aspectos específicos del procedimiento de aplicación del Impuesto sobre Bienes Inmuebles, el Impuesto sobre Actividades Económicas y el Impuesto sobre Vehículos de Tracción Mecánica (en particular, aquellos trámites o actuaciones que se encuentran encomendadas a órganos pertenecientes a la Administración estatal). 
denanza fiscal un determinado aspecto del procedimiento de aplicación de sus tributos; se podría acudir a lo dispuesto en una norma reglamentaria estatal de desarrollo de la LGT o demás reguladoras de la materia. Es en este sentido en el que debe interpretarse, creemos, la remisión que a tales disposiciones reglamentarias se mantiene actualmente en el art. 12.1 TRLHL.

De otro lado, fruto de la aplicabilidad de la LGT a los procedimientos gestores locales es la posible traslación a este ámbito del esquema de gestión diseñado en dicha Ley estatal; aunque conviene no olvidar que este texto legal ha sido diseñado fundamentalmente pensando en tributos con una determinada estructura ${ }^{76}$, y que han de ser aplicados por una específica Administración, la estatal, que cuenta con determinados medios materiales, técnicos y humanos, esto es, con un potencial personal y material, e incluso con un modo de actuar administrativo, que no se asimila al de la mayoría de los Entes locales. Esta circunstancia no ha pasado desapercibida al propio legislador, que desde 1998 ha reconocido expresamente a las Entidades locales el poder normativo para adaptar, a través de sus respectivas Ordenanzas fiscales, el contenido de la referida normativa estatal a su propio régimen de organización y funcionamiento interno ${ }^{77}$; aunque con una limitación importante, ya que, en ningún caso, dicha adaptación podrá ser contraria al contenido material de esa normativa (apartado 2 del art. 12 TRLHL). Pueden, por tanto, a través de sus Ordenanzas fiscales, ordenar el desarrollo de la gestión de sus tributos propios, coordinando los medios personales, técnicos y humanos con los que efectivamente cuentan, así como, ajustar dicha normativa estatal al particular modo de ejercicio o ejecución de las funciones que le son propias que tiene el Ente local; es decir, al propio modo de actuar corriente y constante de la Administración local, o dicho en otros términos, a los propios usos y costumbres de actuación de esta Administración ${ }^{78}$.

Ahora bien, una vez más hemos de reinterpretar el contenido del art. 12.2 del TRLHL a partir de lo dispuesto en la Disposición Adicional Cuarta de la LGT, y poner en cuarentena las anteriores afirmaciones. Si volvemos a leer

\footnotetext{
${ }^{76}$ Atendiendo, fundamentalmente, al Impuesto sobre la Renta de las Personas Físicas y al Impuesto sobre Sociedades y, en menor medida, al Impuesto sobre el Valor Añadido.

77 Es cierto que las Entidades locales gozaban de esta potestad antes de que se hiciese una referencia expresa a la misma en este precepto de la LRHL (en la actualidad, Texto refundido), es decir, antes de su incorporación por la Ley 50/1998, de 30 de diciembre, de Medidas Fiscales, Administrativas y del Orden Social; pues ya en el art. 4.1.a) de la LBRL se reconocía expresamente la potestad de autoorganización de los Entes locales necesarios, y ello evidentemente supone la posibilidad de organizar internamente los servicios de gestión tributaria en general.

${ }^{78}$ No se puede olvidar que en esta labor de adaptación, en ningún caso, podrá contravenirse el contenido material de la normativa legal estatal, que regula esta materia. Sin perjuicio de que es bastante complicado determinar o concretar los términos exactos de esta limitación (qué puede identificarse como contenido material en este caso); de lo que no cabe duda, es que la Entidad local, en este proceso de adaptación del desarrollo material de sus actuaciones procedimentales, habrá de respetar los elementos esenciales o básicos del procedimiento de aplicación, tal y como han sido diseñados en las normas de referencia.
} 
PODER TRIBUTARIO LOCAL Y RESERVA DE LEY ANTE LA PRÓXIMA REFORMA...

dicha Disposición, comprobamos fácilmente que en ella se habla de «desarrollo de lo dispuesto en esta ley» (refiriéndose, obviamente, a la LGT), y no meramente de «adaptar (...) al régimen de organización y de funcionamiento interno», como hace el art. 12 TRLHL. Ello es lógico, si se tiene en cuenta que, para encontrarnos ante una actuación adaptada en sentido propio, es preciso que las disposiciones legales del Estado tengan un desarrollo reglamentario estatal; en el caso de que no sea así, no cabría hablar de «adaptación», sino que se trataría más bien de una actuación de «desarrollo» reglamentario en sentido propio ${ }^{79}$. Dado que en la Disposición Adicional Cuarta de la LGT se les está confiriendo a los Entes locales la posibilidad de desarrollar directamente lo dispuesto en ella, carece de sentido la restricción que en el apartado 2 del art. 12 se les hace, limitando su ámbito de actuación a la mera adaptación del contenido de la normativa legal y reglamentaria estatal. Evidentemente, como cualquier otro reglamento ejecutivo, la Ordenanza fiscal no podrá, en ningún caso, contradecir el contenido de la Ley; y de igual forma, aquellos aspectos de la aplicación de los tributos locales sobre los que la LGT y el resto de la normativa legal estatal aplicable no se pronuncien, podrán ser regulados directamente por la Entidad local ${ }^{80}$.

Concluyendo, en virtud del contenido de esta Disposición Adicional de la LGT, pueden los Entes locales desarrollar, y no meramente adaptar, el contenido de este Texto legal en cualquier aspecto, y en particular, respecto al procedimiento de aplicación de sus tributos; con esta modificación se ha dado un significativo paso hacia delante, y creemos que irreversible, en la atribución a los Entes locales de un mayor protagonismo en la normación de sus propios tributos. Sólo queda esperar que dichos Entes se decidan a hacer uso de estas facultades normativas que se les han conferido, animarles a que desarrollen lo establecido en la LGT, y a que no se limiten a reproducir literalmente lo dispuesto en ella sin añadir nada más. Al respecto, y extrapolando al plano general el argumento que se ha utilizado en relación exclusivamente a los beneficios fiscales, este comportamiento inhibitorio o práctica que siguen muchas Corporaciones locales, limitándose a realizar una mera transcripción del precepto legal de que se trate, sin realizar ninguna labor de integración, cuando la propia norma les habilita o confiere la posibilidad de

\footnotetext{
79 Vid. Rubio de Urquía, J.I.: «Alcance de la potestad normativa de las Entidades locales...», cit., p. 94.

${ }^{80}$ Se produce, en cualquier caso, una situación paradójica y bastante llamativa. Como estamos viendo, en esta materia podrán los Entes locales, dentro de su ámbito de competencias, desarrollar directamente lo dispuesto en la LGT; y en caso de que exista una divergencia entre un reglamento estatal y otro local, y se trate de la aplicación de un tributo local, debemos entender que prevalecerá lo dispuesto en el segundo, siempre y cuando no sea contrario al tenor de la Ley. Ahora bien, la respuesta no es aparentemente tan sencilla cuando la divergencia surge entre dos disposiciones reglamentarias, nuevamente estatal y local, dictadas en desarrollo del TRLHL (recordemos que conforme a la Disposición Final Única de este texto normativo, puede el gobierno dictar disposiciones de desarrollo y ejecución de esta Ley). En este caso, la cuestión debería ser resuelta en el mismo sentido anterior por el principio de especialidad normativa, haciendo prevalecer lo dispuesto en la Ordenanza fiscal local siempre y cuando no sea contraria a lo establecido en la Ley.
} 
integrar o desarrollar el texto legal; contraviene el espíritu de la Ley, que es el de reforzar su autonomía, ejerciendo el poder tributario que le otorga la Constitución ${ }^{81}$.

\section{CONCLUSIÓN}

Hemos visto cómo se ha producido un relativo avance en los últimos años, ampliándose las facultades normativas de las Corporaciones locales sobre sus tributos propios; fruto de una profusa labor doctrinal, que ha venido propugnando la necesidad de otorgar mayores márgenes de decisión a estas entidades, de la jurisprudencia que, si bien con altibajos, ha ido paulatinamente reforzando la autonomía local, llegando incluso a equipararla a la de las Comunidades Autónomas (STC 168/2004, de 6 de octubre, F.J. 4), con la importancia e implicaciones que ello supone; y cómo no, del propio legislador a rémora de lo anterior. De este modo, poco a poco se ha ido incrementando la capacidad del Ente local para dar una cierta orientación propia a su sistema tributario, atendiendo a su específica realidad y necesidades; aunque no es menos cierto que con pasos que han supuesto, hasta la fecha, un avance insuficiente.

Es necesario, por tanto, que de cara a la futura reforma del Gobierno y de la Administración local, esta tendencia se consolide, reforzándose significativamente la potestad normativa de los Entes locales en todos los ámbitos, y en consecuencia, también en el tributario, tan preciso para consolidar definitivamente su autonomía financiera y su suficiencia de recursos; reforzamiento que resulta necesario si se quiere, como así se pretende, o al menos se ha dejado constancia de ello, que la Corporación local sea capaz de dar respuesta a las demandas ciudadanas innovando el ordenamiento jurídico; invocándose en este sentido un Derecho a la espontaneidad del Gobierno local, consecuencia inevitable de la proclamación de una presunción de competencia universal, como se viene a reconocer en el Libro Blanco presentado en 2005. Esperemos a ver qué pasa en el futuro al respecto.

81 Vega Herrero, M., op. cit., p. 2172. 